\title{
SUSTAINABLE TIMBER AND FUEL WOOD PRODUCTION: A NEW APPROACH
}

\author{
K Ajith L D Silva \\ Extension and Communication Centre \\ Department of Agriculture, Peradeniya
}

Forests can be ranked in the foremost frontier in mankind. This natural resource, which is one of the most important resource has fostered the mankind from its beginning to sustain its life and continue to do so even though man does not realize and respect for it.

Currently, the worldwide anthropogenic deforestation is ever increasing and the man has engaged in this destructive process due to the shortsighted greediness and negligence. The services obtained from forests is no second to any other services enjoyed by man.

In addition to encroachments of forests, high rate of timber and fuel wood extraction led to the diminishing of forest cover today.

A tree planting programme followed by a careful management system in suitable locations can reduce the pressure on natural forests for timber. The most feasible way of achieving this is by organizing programmes with the participation of school children. Policies also should be formulated to utilize the school promises to grow valuable and suitable timber species. This task should be delegated to the school children where by they will raise funds for the development of the school while fulfilling a national responsibility. Such a programme drawn for 1000 schools may contribute Rs. 2000 million in every 10 years.

Similarly, a sustainable fuel wood planting campaign can also be launched in the identified scrublands of Sri Lanka. This would greatly reduce the energy crisis in the country while providing a large number of employment opportunities and protecting the natural environment.

Proceedings of the Third Annual Forestry Symposium 1997, of the Department of Forestry and Environmental Science, University of Sri Jayewardenepura, Sri Lanka 